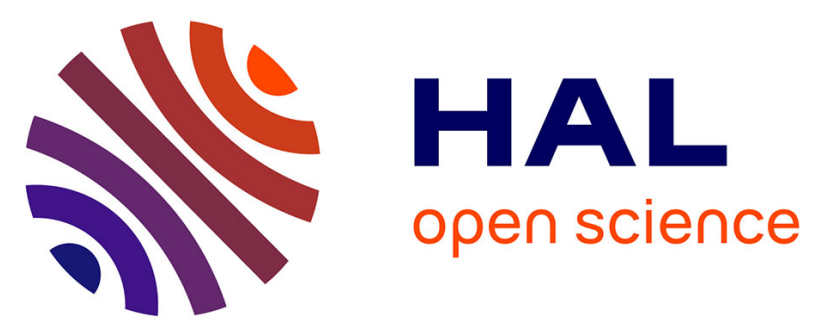

\title{
Temperature stable BaSrTiO3 thin films suitable for microwave applications
}

Kevin Nadaud, Caroline Borderon, Raphaël Gillard, Erwan Fourn, Raphaël Renoud, Hartmut W. Gundel

\section{- To cite this version:}

Kevin Nadaud, Caroline Borderon, Raphaël Gillard, Erwan Fourn, Raphaël Renoud, et al.. Temperature stable BaSrTiO3 thin films suitable for microwave applications. Thin Solid Films, 2015, 591, pp.90-96. 10.1016/j.tsf.2015.08.019 . hal-01186520

\section{HAL Id: hal-01186520 \\ https://hal.science/hal-01186520}

Submitted on 25 Aug 2015

HAL is a multi-disciplinary open access archive for the deposit and dissemination of scientific research documents, whether they are published or not. The documents may come from teaching and research institutions in France or abroad, or from public or private research centers.
L'archive ouverte pluridisciplinaire HAL, est destinée au dépôt et à la diffusion de documents scientifiques de niveau recherche, publiés ou non, émanant des établissements d'enseignement et de recherche français ou étrangers, des laboratoires publics ou privés. 


\title{
Temperature stable $\mathrm{BaSrTiO}_{3}$ thin films suitable for microwave applications
}

\author{
Kevin Nadaud ${ }^{\mathrm{a}, *}$, Caroline Borderon ${ }^{\mathrm{a}}$, Raphaël Gillard ${ }^{\mathrm{b}}$, Erwan Fourn ${ }^{\mathrm{b}}$, Raphaël Renoud ${ }^{\mathrm{a}}$, \\ Hartmut W. Gundel ${ }^{\mathrm{a}}$ \\ ${ }^{a}$ IETR, UMR CNRS 6164, University of Nantes, Nantes, France \\ ${ }^{b}$ IETR, UMR CNRS 6164, INSA of Rennes, Rennes, France
}

\begin{abstract}
In this paper, the properties of an optimized $\mathrm{BaSrTiO}_{3}$ thin film, deposited on an alumina substrate using a sol-gel process, are presented. The real and imaginary parts of the permittivity and the tunability have been measured over 7 decades of frequency and in a temperature interval of $320^{\circ} \mathrm{C}$, which provides a good knowledge of the material properties for microwave applications. The dielectric properties of the films show a good stability in frequency and in temperature. From $-80^{\circ} \mathrm{C}$ to $20^{\circ} \mathrm{C}$, the permittivity changes less than $2 \%$ and from $-75^{\circ} \mathrm{C}$ to $100^{\circ} \mathrm{C}$, the tunability stays higher than $90 \%$ of its maximum value. The frequency dependence of the relative permittivity of the thin film is rather small since it only varies from 375 at $1 \mathrm{kHz}$ to 350 at $5 \mathrm{GHz}$. As a main consequence, the tunability which attains almost $60 \%$ under a bias field of $400 \mathrm{kV} / \mathrm{cm}$, is very stable in frequency up to $5 \mathrm{GHz}$. The dielectric losses $\tan \delta$, measured up to $1 \mathrm{GHz}$, stay below 0.02 for the complete frequency range. Although the material is in the ferroelectric phase, the hysteresis effect is quite negligible, which results in a well-determined permittivity value for a given electric bias field. The characterized thin film has been integrated into a reflectarray cell allowing a dynamic control of the reflected phase. The measured phase-shift value is close to the simulated one, showing the performance of the material.
\end{abstract}

Keywords: Ferroelectric, microwave, temperature, stability

${ }^{*}$ Corresponding author, Tel.: +33276645138 ; fax: +33 240140987.

Email address: kevin.nadaud@etu.univ-nantes.fr (Kevin Nadaud) 


\section{Introduction}

Due to their tunable dielectric permittivity, ferroelectric materials are more and more integrated into microwave components, thus allowing to realize reconfigurable devices [1-3]. Moreover, the use of these materials results in a reduction of the power consumption due to low leakage currents. For microwave applications, it is necessary to obtain a high tunability (variation of the relative permittivity under an applied bias field) and low dielectric losses, which is not obvious as both phenomena are linked. To account for this, a Figure of Merit $\left(F_{O} M\right)$ is used in order to compare the materials and to reflect the fact that a high tunability has no benefit if the dielectric losses are high [4]:

$$
F_{O} M=\frac{n_{r}}{\tan \delta \times 100},
$$

where $\tan \delta$ corresponds to the dielectric losses and $n_{r}$ to the relative tunability which is determined with the classical definition [4]:

$$
n_{r}=\frac{\varepsilon_{r}(0)-\varepsilon_{r}(E)}{\varepsilon_{r}(0)} \times 100,
$$

with $\varepsilon_{r}(0)$ and $\varepsilon_{r}(E)$ the permittivity without and under the bias electric field $E$, respectively. Previous works on different ferroelectric materials report typical FoM values below 30 [5-7]. For the calculation of the $F_{O} M, \tan \delta$ is multiplied by 100 in order to convert it into percent and to have a homogeneity with the tunability (also given in percent). $\tan \delta$ is then given in absolute to correspond to the delay between the applied field and the electric displacement.

For most applications, a stability of the dielectric properties with temperature is required. As ferroelectrics are also pyroelectric, it is necessary to study the temperature dependence of the dielectric permittivity and the losses. Although BST is one of the most studied ferroelectrics for microwave applications, the temperature dependence of its dielectric properties is rarely reported $[6,8,9]$.

Numerous techniques have been employed to increase the temperature stability of ferroelectric thin films. The use of a composition gradient is one of the most used approaches which has been applied in the case of pulsed laser deposition [10] or for sol-gel synthesis [11]. 
A composition gradient introduces a variation of the Curie temperature that is supposed to flatten the temperature response of the material. The presence of internal stress between the different layers may explain the stability according to Zhu et al [10], too. A progressive dopant rate can also be used to reduce the temperature dependence [9]. More complex techniques can be employed such as an association in "parallel" of materials with different Curie temperatures as described in [12]. The variation of permittivity of one layer compensates the variation of the other one, which results in an increased temperature stability between the two Curie temperatures. This more complex technique needs the use of an intermediate layer in order to ensure the absence of a composition gradient.

In the present work, the dielectric properties (permittivity, losses and tunability) of a $1 \%$ manganese-doped $\mathrm{Ba}_{0.80} \mathrm{Sr}_{0.20} \mathrm{TiO}_{3}$ (BST 80/20) thin film are studied as a function of temperature and frequency and the FoM is determined. The ratio of $\mathrm{Ba} / \mathrm{Sr}$ has been chosen to obtain a material in the ferroelectric phase at ambient temperature [13], which results in a higher permittivity and tunability. BST 80/20 is a soft ferroelectric (easy to polarize/depolarize) with a low coercive field which facilitates the electric command of the tunable device. 1\% manganese doping in substitution of the Ti-ions has been employed in order to reduce the low frequency diffusion and high frequency losses [14]. Electron acceptor doping permits us to compensate for oxygen vacancies which are the main defects that contribute to the conduction losses in ferroelectric thin films [14-16]. Moreover, manganese doping helps reduce the domain wall motion contribution to the permittivity which is very dissipative [14].

\section{Experiments}

The manganese-doped $\mathrm{Ba}_{0.80} \mathrm{Sr}_{0.20} \mathrm{TiO}_{3}$ thin films were realized by a modified sol-gel process based on the use of an alkoxide precursor [17]. The dilution was optimized in order to obtain a large grain size and to reduce the strain in the film [18]. The solution was deposited on platinum coated alumina substrates at $4000 \mathrm{rpm}$ during $20 \mathrm{~s}$ and the samples were annealed during $15 \mathrm{~min}$ in a pre-heated open air furnace at $750{ }^{\circ} \mathrm{C}$. Direct annealing (without a prior drying stage) was preferred in order to obtain a larger average grain size due 


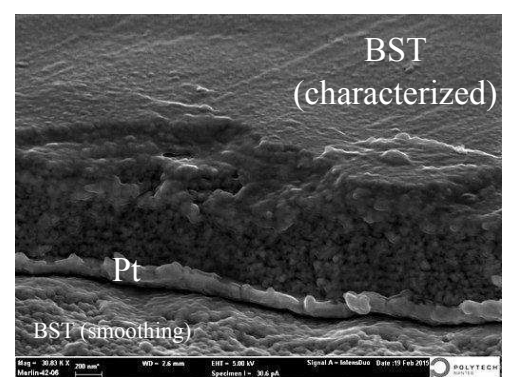

(a)

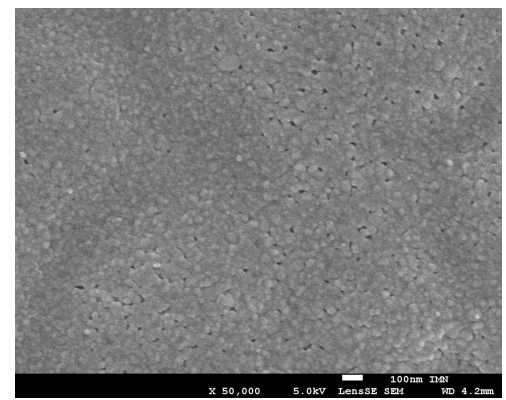

(b)

Figure 1: Cross section (a) and surface (b) SEM micrograph of the deposited thin film.

to a nucleation and crystallization at the layer interface (heterogeneous nucleation) [19]. This is supposed to result in an increased permittivity of the material $[20,21]$. The layer by layer crystallization is well visible on the cross-section micrograph shown in Fig. 1a (examinated with Jeol 7600 scanning electron microscope (SEM)). Fourteen layers have been deposited, resulting in an overall films thickness of typically $0.925 \mu \mathrm{m}$ and a grain size of approximately $65 \mathrm{~nm}$. As can be seen in Fig. 1a, the alumina substrates are smoothed with 7 layers of BST before the deposition of the platinum. This allows reducing the roughness of the substrate which is supposed to increase conduction losses in the bottom electrode. The surface of the thin film is presented in Fig. 1b. It shows a smooth and dense micro-structure without crack.

Due to the polycrystalline nature of the alumina substrate, the BST film does not have a preferential orientation as it can be seen from the X-ray diffraction (XRD) pattern (Fig. 2) performed with a Siemens D5000 diffractometer using the $\mathrm{CuK}_{\alpha}$ radiation. The film is well crystallized and no parasitic peak is visible.

Two different top electrode geometries were used for our studies. For the low frequency 


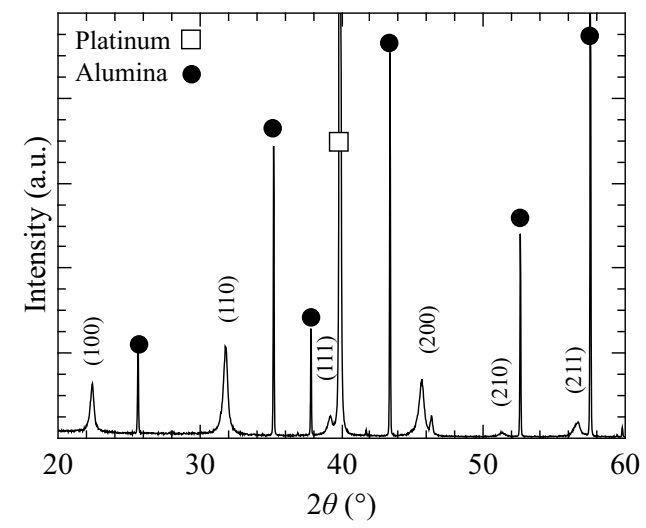

Figure 2: X-ray diffraction pattern of the elaborated thin film on a platinum coated alumina substrate.

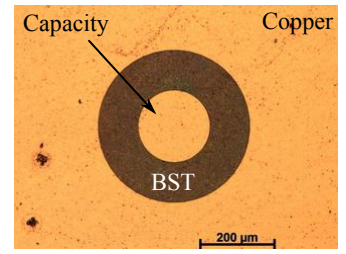

(a) $d=200 \mu \mathrm{m}$

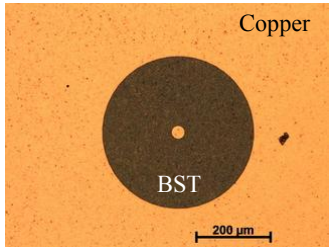

(b) $d=40 \mu \mathrm{m}$

Figure 3: Electrode topology used for the high frequency characterization.

dielectric measurements as a function of temperature, square platinum electrodes of $0.5 \times$ $0.5 \mathrm{~mm}^{2}$ surface area were deposited by RF sputtering in order to obtain the Metal Insulator Metal (MIM) topology. Platinum was chosen here because it does not oxidize even at high measuring temperatures. The capacitance and the dielectric losses were measured with an Agilent $4294 \mathrm{~A}$ impedance meter at an AC field of $0.5 \mathrm{~V} / \mu \mathrm{m}$ and the dielectric permittivity was calculated from the measured capacitance. Negative temperatures were obtained by cooling the sample with liquid nitrogen in a home-made cryostat and temperature controlling was done with an ITC 503 controller. This permits us to measure the dielectric properties between $-150^{\circ} \mathrm{C}$ and $170{ }^{\circ} \mathrm{C}$ and as a function of frequency up to $10 \mathrm{MHz}$.

For the characterizations above $10 \mathrm{MHz}$, the capacitance and the dielectric losses were measured using an Agilent E8364B vector network analyzer with an output power of $-17 \mathrm{dBm}$. In this case, circular top electrodes of different diameter were used (Fig. 3), allowing contacting with a ground-signal-ground (GSG) probe. For these electrodes, copper was deposited by DC sputtering and was patterned with a standard photolithography process. Copper has 


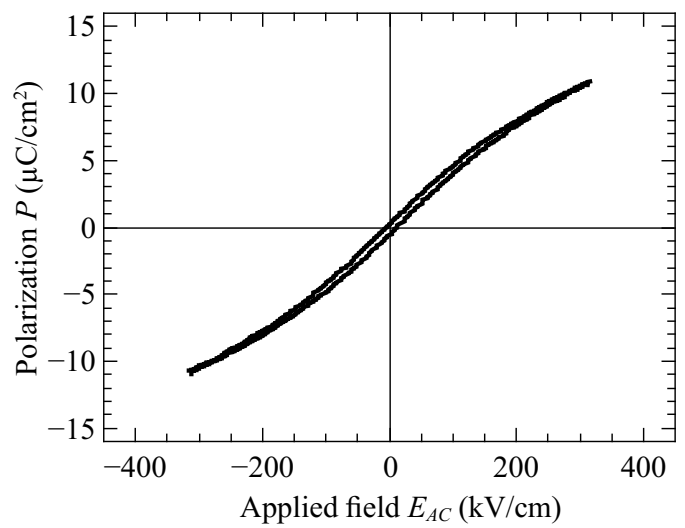

Figure 4: $P-E$ hysteresis loop of the proposed thin film measured at $100 \mathrm{kHz}$ and at room temperature.

a higher conductivity compared to platinum and was preferred in order to obtain a more precise measurement of the material's dielectric losses. The effect of the ground was removed using the technique described in [22].

\section{Results and discussion}

In order to verify the ferroelectric character of the BST thin film, the $P-E$ loop was measured using a classical Sawyer-Tower circuit. The $P-E$ loop of the material, measured at $50 \mathrm{~Hz}$ and at room temperature, is shown in Fig. 4. The material presents a very slim shaped hysteresis loop, which comes from the fact that BST is a soft ferroelectric (easy to polarize/depolarize [23]), with a rather small coercive field $(10 \mathrm{kV} / \mathrm{cm})$. Moreover, the loop is very narrow, which reveals small losses at low frequency. Small losses at low frequency are necessary to prevent from breakdown of the film when a DC bias field is applied.

\subsection{Temperature stability}

The relative permittivity and the dielectric losses as a function of temperature are shown in Fig. 5. Contrary to a single-crystal, there is no abrupt transition and the evolution of the relative permittivity is smooth, which has already been reported in [24]. In our case, the BST has no preferential orientation, the grain size is quite small and the substrate induces stress inside the film which may explain the slow temperature evolution [25]. In the ferroelectric phase, below $60^{\circ} \mathrm{C}$, the relative permittivity is quite stable, at higher temperatures, in the 


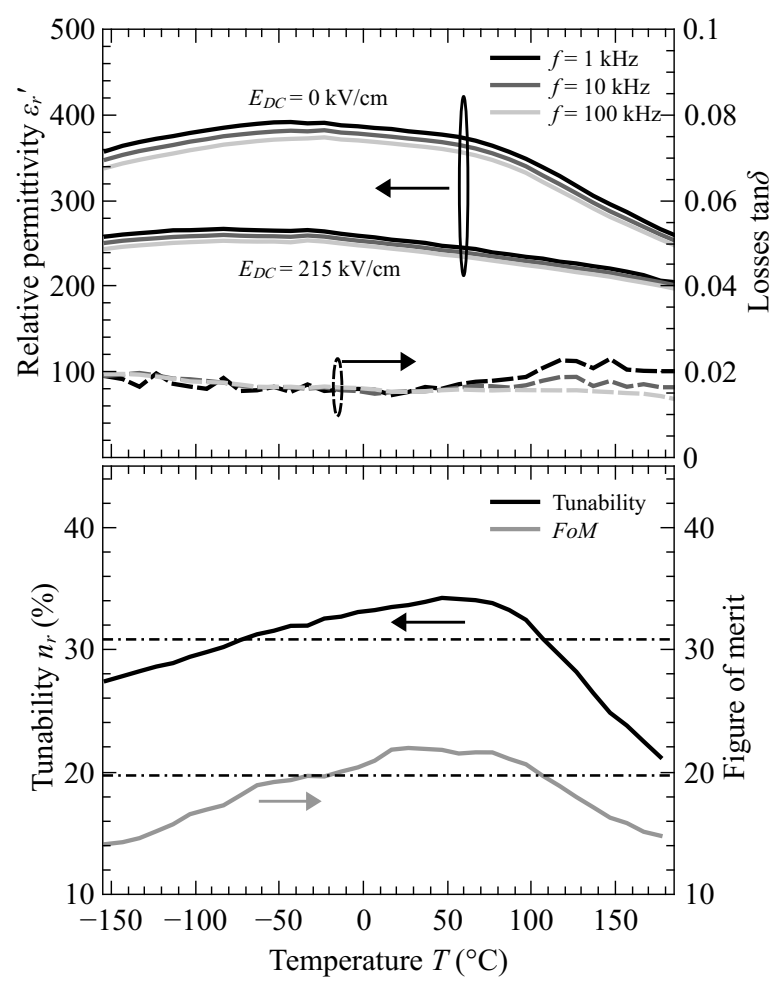

Figure 5: Relative permittivity without and at $215 \mathrm{kV} / \mathrm{cm}$ bias field and dielectric losses for different frequencies (top) and tunability and $F o M$ under $215 \mathrm{kV} / \mathrm{cm}$ bias field at $100 \mathrm{kHz}$ (bottom) of the thin film as a function of temperature.

paraelectric phase, it significantly drops with a slope of $-0.9^{\circ} \mathrm{C}^{-1}$. The relative permittivity varies less than $2 \%$ between $-80^{\circ} \mathrm{C}$ and $20^{\circ} \mathrm{C}$ which shows the good temperature stability of the material. In addition, the dielectric losses vary slowly with temperature. At low temperatures, a slight increase is visible for all frequencies which has already been reported in $[6,9]$. The increase at high temperatures, more visible for low frequencies, comes from the diffusion of charge carriers which increases when the temperature increases $[26,27]$. In the case of ferroelectrics, the low frequency diffusion is generaly attributed to an extrinsic contribution like electronic conduction or oxygen vacancy migration $[16,27,28]$. In the case of acceptor-doped ferroelectrics (manganese in our case), the charge carrier diffusion is generally attributed to oxygen vacancy migration $[16,27]$. The charge carrier diffusion is not visible at high frequencies $(100 \mathrm{kHz})$. From $-40{ }^{\circ} \mathrm{C}$ to $170{ }^{\circ} \mathrm{C}$, the value of $\tan \delta$ at $100 \mathrm{kHz}$ is comprised between 0.016 and 0.015 and the dielectric losses at $-150{ }^{\circ} \mathrm{C}$ are 0.02 .

The stability of the dielectric properties of the elaborated thin films is compared to 


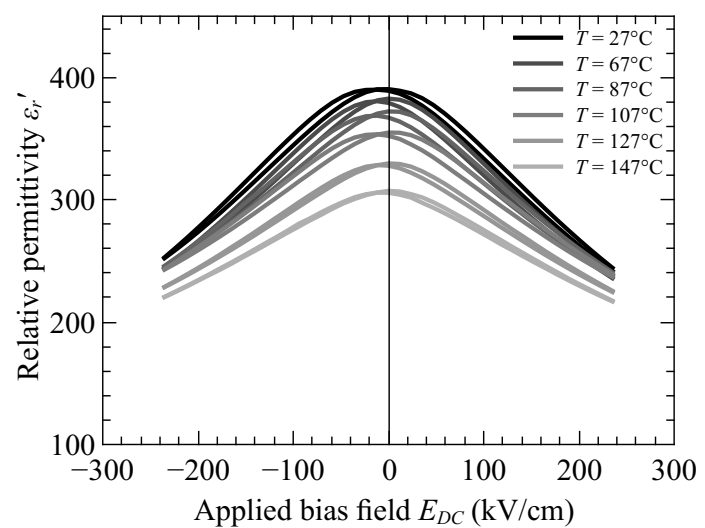

Figure 6: Relative permittivity at $10 \mathrm{kHz}$ as a function of the bias field for different temperatures.

the data from literature in Table 1 . The band $B^{\varepsilon_{r}}$ corresponds to the temperature range where the variation of the material's relative permittivity is less than $2 \%$. Our criterion has been preferred to the temperature coefficient of capacitance $(T C C=\Delta C / C \Delta T)[11]$ which depends on the temperature and does not directly show the temperature interval where the permittivity is stable. The $2 \%$ value has been chosen in accordance to the standard of high value commercial capacitors [29]. The $B^{\varepsilon_{r}}$ band value of our work is slightly larger than reported by Tiggelman et al [6] who used a similar substrate and process. The band is also larger than that of the gradient-composition films developed by Cole et al [11]. However, the $B^{\varepsilon_{r}}$ value of the material developed by Gevorgian et al $[12]$ is higher $\left(190{ }^{\circ} \mathrm{C}\right.$ vs $\left.100{ }^{\circ} \mathrm{C}\right)$ proving that the "parallel" approach is very efficient, although complex. The stability of the losses is shown in the Table 1 , too. In this case, the $B^{\tan \delta}$ value corresponds to a variation of the losses less than $10 \%$. For all the materials, the losses are quite stable except for the MgO-doped BST with a composition gradient developed by Cole et al in [8].

In order to determine the tunability of the BST thin film as a function of temperature, an electric bias field of $215 \mathrm{kV} / \mathrm{cm}$ (corresponding to $20 \mathrm{~V}$ ) has been applied. The evolution of the permittivity under bias shows a similar behavior as function of temperature than without electric field. However, the slope is less pronounced (Fig. 5). Due to the slow variations of the permittivity (with and without bias field), the tunability remains high within the temperature range from $-75^{\circ} \mathrm{C}$ to $100{ }^{\circ} \mathrm{C}$. Above this temperature, a rapid decrease of the 
Table 1: Comparison of the temperature stability of different thin films. The arrows indicate a composition gradient from the top to the bottom layer. Additional indication of an element signifies a doping gradient. The two vertical bars indicate that the compositions are connected in "parallel". Listing is by increasing approach complexity.

\begin{tabular}{|c|c|c|c|c|c|}
\hline Composition & Substrate & $B^{\varepsilon_{r}}$ & $B^{\tan \delta}$ & $B^{F o M}$ & Reference \\
\hline $80 / 20$ & $\mathrm{Al}_{2} \mathrm{O}_{3}$ & $\begin{array}{c}{\left[-60^{\circ} \mathrm{C}\right.} \\
\left.35^{\circ} \mathrm{C}\right]\end{array}$ & $\begin{array}{c}{\left[-10^{\circ} \mathrm{C}\right.} \\
\left.95^{\circ} \mathrm{C}\right]\end{array}$ & $\mathrm{NC}$ & {$[6]$} \\
\hline $80 / 20$ & $\mathrm{Al}_{2} \mathrm{O}_{3}$ & $\begin{array}{c}{\left[-80^{\circ} \mathrm{C}\right.} \\
\left.20^{\circ} \mathrm{C}\right]\end{array}$ & $\begin{array}{c}{\left[-40^{\circ} \mathrm{C}\right.} \\
\left.170^{\circ} \mathrm{C}\right]\end{array}$ & $\begin{array}{c}{\left[-20^{\circ} \mathrm{C}\right.} \\
\left.100^{\circ} \mathrm{C}\right]\end{array}$ & $\begin{array}{l}\text { This } \\
\text { work }\end{array}$ \\
\hline $60 / 40 \rightarrow 90 / 10$ & $\mathrm{Si}$ & $\begin{array}{c}{\left[-10^{\circ} \mathrm{C}\right.} \\
\left.20^{\circ} \mathrm{C}\right]\end{array}$ & {$\left[0{ }^{\circ} \mathrm{C}, 20^{\circ} \mathrm{C}\right]$} & $\begin{array}{l}{\left[10^{\circ} \mathrm{C}\right.} \\
\left.20^{\circ} \mathrm{C}\right]\end{array}$ & {$[8]$} \\
\hline $60 / 40 \rightarrow 90 / 10$ & $\mathrm{Si}$ & $\begin{array}{c}{\left[-10^{\circ} \mathrm{C}\right.} \\
\left.50^{\circ} \mathrm{C}\right]\end{array}$ & {$\left[0^{\circ} \mathrm{C}, 80^{\circ} \mathrm{C}\right]$} & {$\left[0^{\circ} \mathrm{C}, 30^{\circ} \mathrm{C}\right]$} & {$[11]$} \\
\hline $\begin{array}{l}50 / 50(1 \rightarrow 5 \rightarrow 1 \\
\mathrm{Mn})\end{array}$ & $\mathrm{LaAlO}_{3}$ & $\begin{array}{c}{\left[-55^{\circ} \mathrm{C}\right.} \\
\left.10^{\circ} \mathrm{C}\right]\end{array}$ & $\begin{array}{l}{\left[75^{\circ} \mathrm{C}\right.} \\
\left.130^{\circ} \mathrm{C}\right]\end{array}$ & $\begin{array}{c}{\left[-10^{\circ} \mathrm{C}\right.} \\
\left.20^{\circ} \mathrm{C}\right]\end{array}$ & {$[9]$} \\
\hline $75 / 25$ || 25/75 & $\mathrm{MgO}$ & $\begin{array}{c}{\left[-160^{\circ} \mathrm{C}\right.} \\
\left.30^{\circ} \mathrm{C}\right]\end{array}$ & $\begin{array}{c}{\left[-130^{\circ} \mathrm{C}\right.} \\
\left.15^{\circ} \mathrm{C}\right]\end{array}$ & $\mathrm{NC}$ & {$[12]$} \\
\hline
\end{tabular}

tunability can be seen. This corresponds to the gradual transition of the material to the paraelectric phase where a smaller number of ferroelectric cells with high permittivity and tunability is present.

The Figure of Merit has been calculated using equation (1) and is reported in Fig. 5. In the temperature range from $-20{ }^{\circ} \mathrm{C}$ to $100{ }^{\circ} \mathrm{C}$, the $F o M$ is higher than 20 at a bias electric field of $215 \mathrm{kV} / \mathrm{cm}$, showing that the stability of the material is good. At higher temperatures, the FoM value decreases with a slope of $-0.1^{\circ} \mathrm{C}^{-1}$. The Figure of merit stability is represented in Table 1 by the band $B^{F o M}$ which is defined as the temperature range where the FoM is higher than $90 \%$ of its maximum value. The thin film studied in our work has the largest band where the FoM stays high. However, due to the lack of data for some materials, it is difficult to compare rigorously.

The evolution of the permittivity as a function of the electric bias field at a frequency of $10 \mathrm{kHz}$ for different temperatures is reported in Fig. 6. As already shown before, the material's tunability decreases with increasing temperature and the permittivity curves become flatter. In the ferroelectric phase, the characteristic butterfly loop due to polarization 


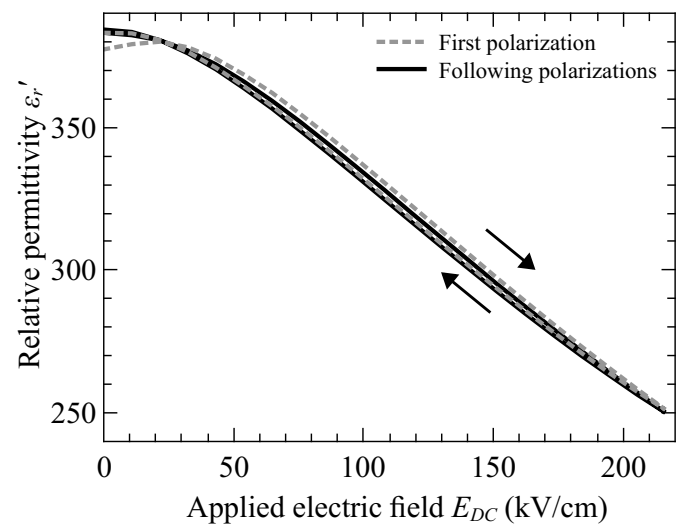

Figure 7: Relative permittivity at $10 \mathrm{kHz}$ and room temperature as a function of the bias field for positive bias field only.

switching is visible, although only weakly pronounced. As the ferroelectric-paraelectric phase transition temperature is approached, the hysteresis effect diminishes and disappears above the Curie temperature.

Mostly, when using a thin film integrated in a device, the bias field will be unipolar. Fig. 7 shows the permittivity as a function of the applied bias field, at room temperature, for positive applied fields only. For the first polarization curve (grey curve), a small hysteresis effect can be seen at low applied fields (below $30 \mathrm{kV} / \mathrm{cm}$ ), which comes from domain switching in the material. For successive cycles, no difference is present at low fields, but a small hysteresis effect is still visible between $50 \mathrm{kV} / \mathrm{cm}$ to $150 \mathrm{kV} / \mathrm{cm}$ (black curve). Nevertheless, the difference of permittivity between the up-going and the down-going field is very small and corresponds to less than $1 \%$. This shows that the hysteresis effect is almost negligible even though the material is in the ferroelectric phase.

In conclusion on the temperature study of the BST thin film, one can note that the material has a large temperature band, corresponding to the ferroelectric phase, where the dielectric properties are rather stable. This stability may be due to the small grain size and the strain from the substrate. As the dielectric losses do not vary significantly and the tunability is quite high in the $-75^{\circ} \mathrm{C}$ to $100^{\circ} \mathrm{C}$ band, the figure of merit stability of our film is better in comparison to what is reported in literature. Microwave applications hence have better profit from a material in its ferroelectric phase. Even if a hysteresis is present, there 


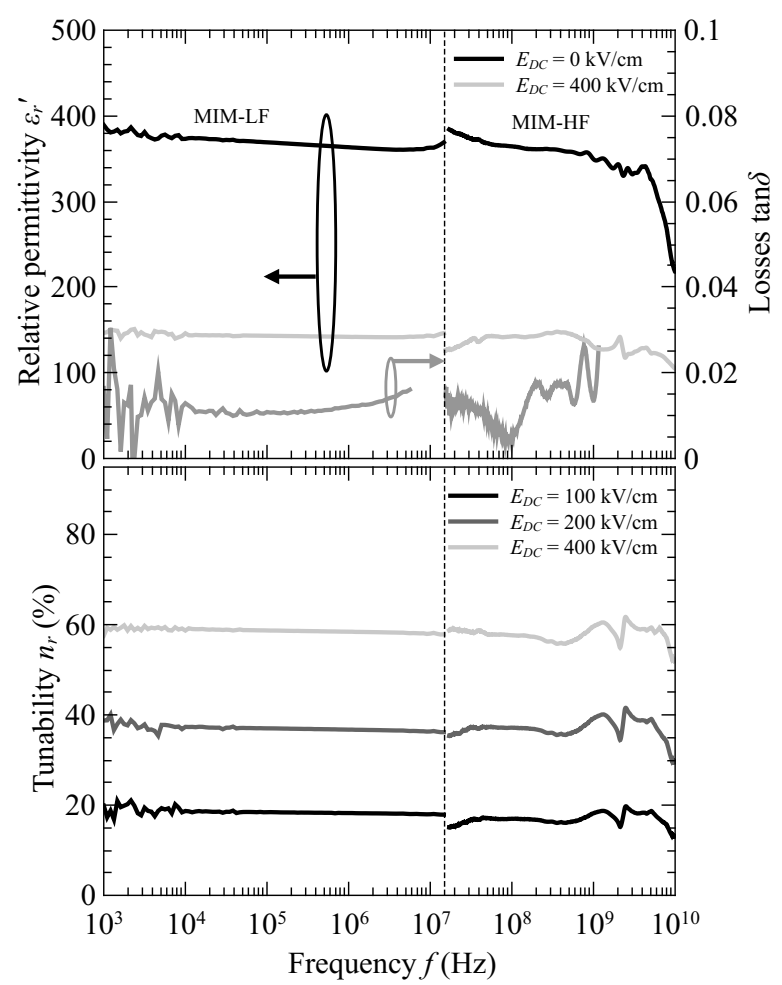

Figure 8: Relative permittivity, dielectric losses and tunablity under $400 \mathrm{kV} / \mathrm{cm}$ bias field as a function of frequency at room temperature. The increase of losses between $1 \mathrm{MHz}$ and $10 \mathrm{MHz}$ is due to a resonance of the fixture of the impedance analyzer and the capacitor.

is a very small difference in permittivity between the up-going and down-going curves. This results in a well-defined permittivity value for a given bias field. Working in the paraelectric phase in order to completely avoid the hysteresis effect would result in a lower tunability and very temperature-dependent properties.

\subsection{Frequency stability}

The complex permittivity has been measured as a function of frequency with the two methods described above. The MIM structure used in the low and the high frequency ranges (MIM-LF and MIM-HF) allows us to apply a similar bias electric field and thus to determine the tunability of the material over almost 7 decades (Fig. 8). The relative permittivity without and with applied bias field slightly decreases with frequency, but no fast variation caused by any relaxation or resonance is visible. Consequently, the tunability remains high up to high frequencies. The obtained value under an applied bias field of 
$400 \mathrm{kV} / \mathrm{cm}$ (corresponding to $37 \mathrm{~V}$ on the $925 \mathrm{~nm}$ thin film) is above $58 \%$. In the $\mathrm{GHz}$ band, the relative permittivity is about 350 at zero bias electric field. The measured value of the dielectric losses $\tan \delta$ is quite stable up to $100 \mathrm{MHz}$ and is slightly higher than 0.01 . All these dielectric data are similar or better to what has been reported elsewhere $[6,11]$. Between $100 \mathrm{MHz}$ and $1 \mathrm{GHz}$, an increase of the dielectric losses up to 0.02 is observed. This may be due to a rather bad conductivity of the bottom electrode, which results in an overestimation of the material's dielectric losses [30]. Nevertheless, the quality factor $(Q=1 / \tan \delta)$ of the capacitor is still 50 at $1 \mathrm{GHz}$, which is higher than measured by Tiggelman et al [6] but lower than reported by Vorobiev et al [31]. The capacitor proposed by Vorobiev has a larger quality factor $(150$ at $1 \mathrm{GHz}$ ), which comes from the use of gold for the bottom electrode in addition to platinum. Moreover, the material is in the paraelectric phase, which reduces the capacitor losses. However, the thin film of the present work has a considerably larger tunability for the same bias field ( $58 \%$ instead of $22 \%$ at $400 \mathrm{kV} / \mathrm{cm}$, extrapolated from the value at $1 \mathrm{MHz}$ for the Vorobiev's material). This results in a FoM around 30 for both materials. Finally, the choice of the material shall depend on the constraints imposed by the device (i.e. if it is preferable to achieve small losses but lower tunability or higher tunability with also more important losses).

The dielectric losses determined in the frequency study are lower than those obtained from the temperature measurements because the top electrode consists of copper. This reflects the importance of the electrode material used for the measurement. Thus, particular attention has to be given to the electrode conductivity, not only to avoid an overestimation of the material's dielectric losses, but also for the application.

The permittivity as a function of the electric bias field at high frequencies is reported in Fig. 9. Contrary to the case of the temperature study, there is a small asymmetry in the $\varepsilon_{r}-E_{D C}$ loop. This is due to the different work function of the top and the bottom electrode metals. This asymmetry may be even beneficial since there is almost no hysteresis effect for a positive bias field. This permits us to have a well-defined value of the permittivity for a given bias. Moreover, the material's tunability almost does not vary up to the GHz region.

The FoM has been plotted as a function of frequency and is shown in Fig. 10. The 


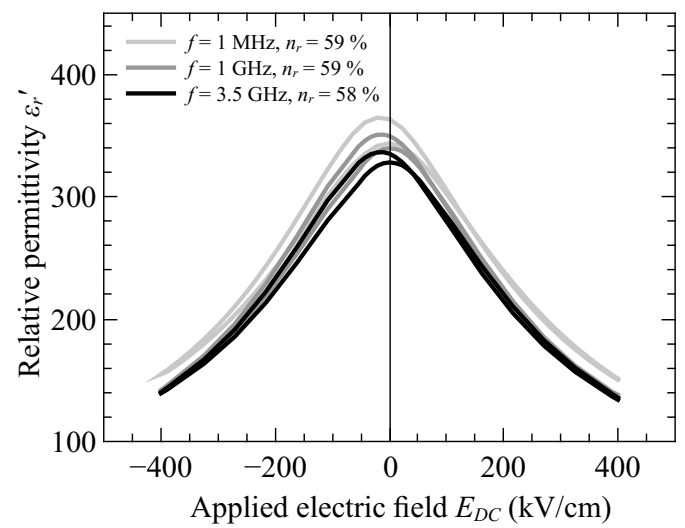

Figure 9: Relative permittivity as a function of the electric bias field for different frequencies at room temperature.

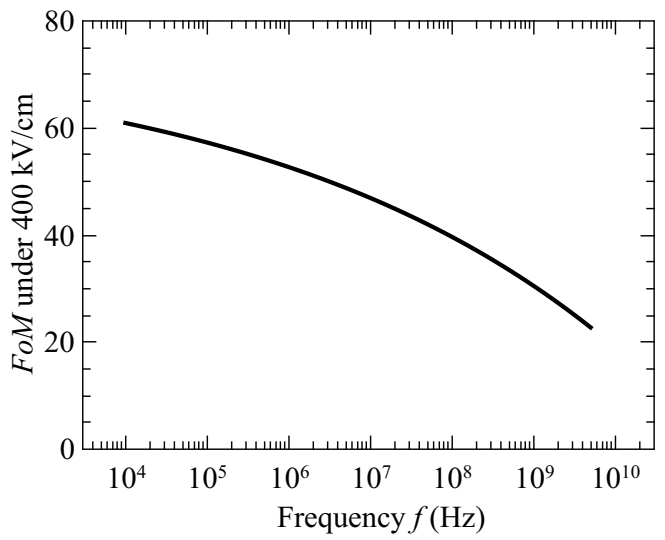

Figure 10: FoM under $400 \mathrm{kV} / \mathrm{cm}$ as a function of frequency.

decrease with frequency is mainly due to an increase of the losses at high frequencies. Nevertheless, the obtained value at $1 \mathrm{GHz}$ is still 30 .

To conclude on the frequency study, one can note that permittivity and tunability of the BST thin film are almost constant from $1 \mathrm{kHz}$ to $1 \mathrm{GHz}$. This shows the excellent frequency stability of the dielectric properties of the proposed material. The dielectric losses measured increase from around 0.01 to 0.015 and finally reach approximately 0.02 at $1 \mathrm{GHz}$. The real material losses should even be smaller since the characterization structure can cause an overestimation of the dielectric losses due to propagation phenomena and the losses in the electrodes [30]. This corresponds to a quality factor of 50 that is higher than measured by Tiggelman et al [6] but lower than reported by Vorobiev et al [31]. 


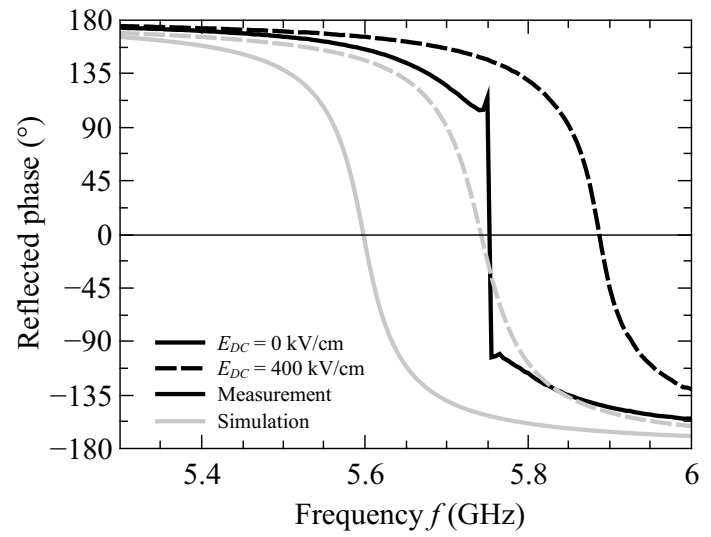

Figure 11: Simulated and measured reflected phase of the realized reflectarray cell.

\subsection{Integration of the material}

The ferroelectric thin film has been integrated into a reflectarray cell in order to show its performance for microwave device applications. The cell consists of a slot in a ground plane. The slot is loaded by a coplanar ferroelectric capacitor which electrical length controls the reflected phase of an incident wave [1]. It is then possible to dynamically change the electrical length of the slot and thus the reflected phase by tuning the ferroelectric permittivity.

The results from measurement and simulation of the reflectarray cell are shown in Fig. 11. The phase-shift provided by the cell under $400 \mathrm{kV} / \mathrm{cm}$ bias electric field is about $245^{\circ}$ as predicted by simulations. The offset of the resonant frequency visible in the figure can be attributed to slightly different geometric dimensions between experiment and simulation. The steep slope of the experimental curve in the case of the unbiased state comes from electrode conduction losses which are higher in experiment than supposed for simulation due to a difference in conductivity of the copper metallization $\left(\sigma_{\text {meas }}=2 \times 10^{7} \mathrm{~S} \mathrm{~m}^{-1}\right.$ instead of $\sigma_{\text {bulk }}=5.8 \times 10^{7} \mathrm{~S} \mathrm{~m}^{-1}$ ). Nevertheless, the agility of the cell is clearly demonstrated and integration of the tunable material has been successful. Moreover, the maximum phase-shift of the device is significant, which paves the way to active microwave components based on ferroelectric thin films. 


\section{Conclusion}

In this paper, a $1 \%$ manganese doped $\mathrm{Ba}_{0.80} \mathrm{Sr}_{0.20} \mathrm{TiO}_{3}$ thin film, deposited on an alumina substrate, has been characterized over 7 frequency decade and in a temperature range larger than $300^{\circ} \mathrm{C}$

The proposed BST film has a good stability in temperature. The permittivity varies less than $2 \%$ between $-80{ }^{\circ} \mathrm{C}$ and $20^{\circ} \mathrm{C}$ and the tunability stays close to its maximum value from $-25^{\circ} \mathrm{C}$ to $100^{\circ} \mathrm{C}$. As the dielectric losses are rather independent from temperature, the $F_{O} M$ is higher than $90 \%$ of its maximum value from $-20^{\circ} \mathrm{C}$ to $100{ }^{\circ} \mathrm{C}$.

A good frequency stability has been demonstrated since the permittivity only slightly decreases from 375 at $1 \mathrm{kHz}$ to 350 at $5 \mathrm{GHz}$ and the material's tunability ( $58 \%$ under a bias electric field of $400 \mathrm{kV} / \mathrm{cm}$ ) is stable for frequencies from $1 \mathrm{kHz}$ to $5 \mathrm{GHz}$. The dielectric losses are below 0.02 up to $1 \mathrm{GHz}$. This results in a FoM of about 30 at $1 \mathrm{GHz}$ which is similar to what has been reported in literature. Even though the material is in the ferroelectric phase, the hysteresis effect is not pronounced, which results in a well-defined permittivity when using a unipolar biasing voltage for tuning the ferroelectric permittivity.

The BST thin film has been inserted in a reflectarray cell and a phase-shift range of $245^{\circ}$ has been demonstrated for a material's tunability of $58 \%$ at $5.8 \mathrm{GHz}$ and room temperature. This shows the potentiality of the ferroelectric material for tunable microwave devices.

\section{Acknowledgement}

The authors would like to acknowledge the CNRS (Centre National de la Recherche Scientifique) and the French Region "Pays de la Loire" for the financial support. The authors are grateful to S. Ginestar for the SEM image.

\section{References}

[1] K. Nadaud, R. Gillard, E. Fourn, H. Gundel, C. Borderon, A simple Phase-Shifting cell for reflectarray using a slot loaded with a ferroelectric capacitor, in: Loughborough Antennas and Propagation Conference, 2014, pp. 214-217.

[2] J. Hai, M. Patterson, D. Brown, Z. Chenhao, P. KuanChang, G. Subramanyam, D. Kuhl, K. Leedy, C. Cerny, Miniaturized and reconfigurable CPW square-ring slot antenna loaded with ferroelectric BST thin film varactors, IEEE Transactions on Antennas and Propagation 60 (7) (2012) 3111-3119. 
[3] A. Ghalem, F. Ponchel, D. Remiens, T. Lasri, A 3.8 GHz tunable filter based on ferroelectric interdigitated capacitors, in: Proc. IEEE Int. Symp. Applicat. Ferroelectrics, 2013, pp. 252-256.

[4] D. Al-Shareef, H N.and Dimos, M. V. Raymond, R. Schwartz, Tunability and calculation of the dielectric constant of capacitor structures with interdigital electrodes, J. Electroceramics 12 (2) (1997) 145-153.

[5] C. Varanasi, K. Leedy, D. Tomich, G. Subramanyam, Large area $\mathrm{Ba}_{x} \mathrm{Sr}_{1-x} \mathrm{TiO}_{3}$ thin films for microwave applications deposited by pulsed laser ablation, Thin Solid Films 517 (9) (2009) 2878-2881.

[6] M. Tiggelman, K. Reimann, M. Klee, R. Mauczock, W. Keur, R. Hueting, $\mathrm{Ba}_{x} \mathrm{Sr}_{1-x} \mathrm{Ti}_{1.02} \mathrm{O}_{3}$ metalinsulator-metal capacitors on planarized alumina substrates, Thin Solid Films 518 (10) (2010) 2854 2859.

[7] D. Ghosh, B. Laughlin, J. Nath, A. Kingon, M. Steer, J.-P. Maria, Tunable high-quality-factor interdigitated $(\mathrm{Ba}, \mathrm{Sr}) \mathrm{TiO}_{3}$ capacitors fabricated on low-cost substrates with copper metallization, Thin Solid Films 496 (2) (2006) $669-673$.

[8] M. W. Cole, E. Ngo, S. Hirsch, M. B. Okatan, S. P. Alpay, Dielectric properties of MgO-doped compositionally graded multilayer barium strontium titanate films, Applied Physics Letters 92 (7) (2008) 072906 .

[9] M. Jain, S. B. Majumder, R. S. Katiyar, F. A. Miranda, F. W. Van Keuls, Improvement in electrical characteristics of graded manganese doped barium strontium titanate thin films, Applied Physics Letters 82 (12) (2003) 1911-1913.

[10] X. Zhu, N. Chong, H. L.-W. Chan, C.-L. Choy, K.-H. Wong, Z. Liu, N. Ming, Epitaxial growth and planar dielectric properties of compositionally graded $\left(\mathrm{Ba}_{1-x} \mathrm{Sr}_{x}\right) \mathrm{TiO}_{3}$ thin films prepared by pulsedlaser deposition, Applied Physics Letters 80 (18) (2002) 3376-3378.

[11] M. W. Cole, E. Ngo, S. Hirsch, J. D. Demaree, S. Zhong, S. P. Alpay, The fabrication and material properties of compositionally multilayered $\mathrm{Ba}_{1-x} \mathrm{Sr}_{x} \mathrm{TiO}_{3}$ thin films for realization of temperature insensitive tunable phase shifter devices, Journal of Applied Physics 102 (3) (2007) 034104.

[12] S. Gevorgian, P. K. Petrov, Z. Ivanov, E. Wikborg, Tailoring the temperature coefficient of capacitance in ferroelectric varactors, Applied Physics Letters 79 (12) (2001) 1861-1863.

[13] V. V. Lemanov, E. P. Smirnova, P. P. Syrnikov, E. A. Tarakanov, Phase transitions and glasslike behavior in $\mathrm{Sr}_{1-x} \mathrm{Ba}_{x} \mathrm{TiO}_{3}$, Phys. Rev. B 54 (1996) 3151-3157.

[14] K. Nadaud, C. Borderon, R. Renoud, H. W. Gundel, Effect of manganese doping of $\mathrm{BaSrTiO}_{3}$ on diffusion and domain wall pinning, Journal of Applied Physics 117 (8) (2015) 084104.

[15] M.-C. Chiu, Y.-C. Lee, F.-S. Shieu, Effect of MgO dopant on the microstructure and dielectric properties of rf-sputtered $\mathrm{Ba}_{0.5} \mathrm{Sr}_{0.5} \mathrm{TiO}_{3}$ thin films, Journal of The Electrochemical Society 152 (11) (2005) 194201.

[16] D. Levasseur, E. Bouyssou, R. De Paolis, A. Rousseau, F. Coccetti, G. Guegan, S. Payan, M. Maglione, Systematic tuning of the conduction mechanisms in ferroelectric thin films, Journal of Physics: Condensed Matter 25 (49) (2013) 495901.

[17] C. Borderon, D. Averty, R. Seveno, H. W. Gundel, Preparation and characterization of barium strontium titanate thin films by chemical solution deposition, Ferroelectrics 362 (2008) 1-7.

[18] C. Borderon, D. Averty, R. Seveno, H. W. Gundel, Influence of the morphology of barium strontium titanate thin films on the ferroelectric and dielectric properties, Integrated Ferroelectrics 93 (1) (2007) $133-140$.

[19] R. Schwartz, T. Schneller, R. Waser, Chemical solution deposition of electronic oxide films, Comptes Rendus Chimie 7 (5) (2004) 433-461.

[20] S. Hoffmann, R. Waser, Control of the morphology of CSD-prepared (Ba,Sr) $\mathrm{TiO}_{3}$ thin films, Journal of the European Ceramic Society 19 (6-7) (1999) 1339-1343.

[21] U. Hasenkox, S. Hoffmann, R. Waser, Influence of precursor chemistry on the formation of $\mathrm{MTiO}_{3}$ $\mathrm{M}=\mathrm{Ba}, \mathrm{Sr}$ ceramic thin films, Journal of Sol-Gel Science and Technology 12 (2) (1998) 67-79.

[22] Z. Ma, A. J. Becker, P. Polakos, H. Huggins, J. Pastalan, H. Wu, K. Watts, Y. H. Wong, P. Mankiewich, RF measurement technique for characterizing thin dielectric films, IEEE Transactions on Electronics Devices 45 (1998) 1811-1816.

[23] D. Damjanovic, Ferroelectric, dielectric and piezoelectric properties of ferroelectric thin films and ce- 
ramics, Reports on Progress in Physics 61 (9) (1998) 1267.

[24] T. M. Shaw, Z. Suo, M. Huang, E. Liniger, R. B. Laibowitz, J. D. Baniecki, The effect of stress on the dielectric properties of barium strontium titanate thin films, Applied Physics Letters 75 (14) (1999) 2129-2131.

[25] J.-G. Cheng, X.-J. Meng, B. Li, J. Tang, S.-L. Guo, J.-H. Chu, M. Wang, H. Wang, Z. Wang, Ferroelectricity in sol-gel derived ba0.8sr0.2tio3 thin films using a highly diluted precursor solution, Applied Physics Letters 75 (14) (1999) 2132-2134.

[26] O. Mekni, H. Arifa, B. Askri, K. Raouadi, G. Damamme, B. Yangui, Trapping-charging ability and electrical properties study of amorphous insulator by dielectric spectroscopy, Journal of Applied Physics 116 (2014) 104104.

[27] M. I. Morozov, D. Damjanovic, Charge migration in $\mathrm{Pb}(\mathrm{Zr}, \mathrm{Ti}) \mathrm{O}_{3}$ ceramics and its relation to ageing, hardening, and softening, Journal of Applied Physics 107 (3) (2010) 034106.

[28] S. Gevorgian, Ferroelectrics in Microwave Devices, Circuits and Systems, Springer-Verlag London, 2009.

[29] 116 series Microcaps ${ }^{\circledR}$, American Technical Ceramics.

[30] M. P. J. Tiggelman, K. Reimann, J. Liu, M. Klee, W. Keur, R. Mauczock, J. Schmitz, R. J. E. Hueting, Identifying dielectric and resistive electrode losses in high-density capacitors at radio frequencies, in: Proc. IEEE Int. Conf. Microelectronic Test Structures, 2008, pp. 190-195.

[31] A. Vorobiev, P. Rundqvist, K. Khamchane, S. Gevorgian, Silicon substrate integrated high Q-factor parallel-plate ferroelectric varactors for microwave/millimeterwave applications, Applied Physics Letters 83 (15) (2003) 3144-3146. 